\title{
Green synthesis of Ag nanoparticles using aqueous extract of Kaempferia galanga Linn. (Zingiberaceae) rhizomes
}

\author{
Satyavama Devi Asem, Warjeet Singh Laitonjam*
}

Department of Chemistry, Manipur University, Canchipur, Imphal-795003, Manipur, India ${ }^{\star}$ Author for corresponding. E-mail address: warjeet@yahoo.com

\begin{abstract}
Green synthesis of noble metal nanoparticles (NPs) is a vast developing area of research. In the present study, silver nanoparticles (Ag-NPs) were rapidly synthesized by treating silver ions through a simple and green synthetic route using water extract of the rhizomes of Kaempferia galanga Linn.(KG), which acted simultaneously as a reductant and stabilizer. The reaction process was monitored using ultraviolet-visible (UV-Vis) spectroscopy. The EPR spectra of AgKG NPs was found to be confined in a single line which showed the presence of an unpaired electron indicating of Ag in neutral state at room temperature. The size and morphology of AgNPs recorded by Scanning electron microscopy (SEM) were further confirmed by transmission electron microscopy (TEM) and selected area electron diffraction (SAED). The formation of AgNPs is evidenced by the appearance of signatory brown colour of the solution. FT-IR spectrum indicates the presence of different functional groups in capping the nanoparticles with K. galanga. Average size range estimated from our studies is 2 to $4 \mathrm{~nm}$. It consists of a spherical like particles.
\end{abstract}

Keywords: Kaempferia galanga; Zingiberaceae; Nanoparticles; Green synthesis

\section{Council for Innovative Research}

Peer Review Research Publishing System

\section{Journal: Journal of Advances in Chemistry}

Vol. 7, No. 2

editor@cirworld.com

www.cirworld.com, member.cirworld.com 


\section{INTRODUCTION}

The application of nanoscale materials and structures, usually ranging from 1 to 100 nanometers (nm), is an emerging area of nanoscience and nanotechnology. The biosynthesis of nanoparticles by green technique which represents a connection between biotechnology and nanotechnology, has received increasing consideration due to the growing need to develop environmentally benign technologies for material syntheses. The "green synthesis" of metal nanoparticles receives greater attention due to their unusual optical, chemical, photo-chemical, and electronic properties [1]. Metal nanoparticles, especially the noble metals, have mainly been studied because of their strong optical absorption in the visible region caused by the collective excitation of the free electron gas [2]. Among noble metal nanoparticles, silver nanoparticles (AgNPs) have a wide area of interest because of the high surface volume fractions so that a large proportion of silver atoms are in direct contact with their environment. Due to these properties, they have a large number of applications in different fields, such as, in non-linear optics, spectrally selective coatings for solar energy absorption, bio-labelling, intercalation materials for electrical batteries as optical receptors, as catalyst in chemical reactions, and as antibacterial capacities [3].

There are several ways to reduce $\mathrm{Ag}^{+}$[4-16], However, the intense use of solvents and synthetic reactants are harmful for the environment. The possibility of using plant materials for the synthesis of nanoscale metals was reported initially by Gardea-Torresdey et al. [17, 18]. There are several reports for the synthesis of AgNPs using extracts of plant materials [19-31]. Herein, we report the green synthesis of AgNPs using water extract of rhizomes of Kaempferia galanga Linn. as the reducing agent.

K. galanga, an aromatic rhizomatous herb, belongs to the family Zingiberaceae. Sterols, triterpenoids, alkaloids, saponins, flavonoids, carbohydrates and proteins have been reported [32]. The essential oil is reported to contain over 54 components of which the major constituents are ethyl-p-methoxycinnamate $(31.77 \%)$, ethylcinnamate (23.23\%), carvone (11.13\%), eucalyptol $(9.59 \%)$, pentadecane $(6.41 \%)$ and borneol $(2.87 \%)$, respectively [33]. Other constituents include 1,8-cineole, $\delta$-carene, undecanone, isopropyl cinnamate, dipentene dioxide, camphene, cymene and apigenin [34-35]. Terpenoid constituents amounted to 16.4\% [36-37]. Insecticidal constituents from K. galanga were isolated by Pandji et al.1993 [38].

In this paper, we report an environmentally friendly, ultrafast, one-step, cost- efficient green method for producing Ag/ K. galanga (AgKG). The AgKG-NPs were prepared using silver nitrate as silver precursor and $K$. galanga rhizomes powder water extract as reducing agent and stabilizer.

\section{Experimental and methods}

\subsection{Materials}

The rhizomes of $K$. galanga were collected from Bishnupur district of Manipur. $\mathrm{AgNO}_{3}(99.98 \%)$ was used as a silver precursor, and was provided by Merck. All reagents in this effort were analytical grade. All glassware used in experimental procedures were cleaned in a fresh solution of $\mathrm{HNO}_{3} / \mathrm{HCl}(3: 1, \mathrm{v} / \mathrm{v})$, washed thoroughly with double distilled water, and dried before use.

\subsection{Preparation of extract}

The rhizomes of $K$. galanga were washed to remove the adhering mud particles and possible impurities. Later, they were dried in sunlight for a week to completely remove the moisture. The tubers were cut into small pieces, powdered in a mixer, and then sieved using a 20-mesh sieve to get a uniform size range. The final sieved powder was used for all further studies. For the production of the extract, $0.25 \mathrm{~g}$ of $K$. galanga rhizome powder was added to a $100-\mathrm{mL}$ flask with $50 \mathrm{~mL}$ sterile distilled water and then mixed for $1 \mathrm{~h}$ in room temperature.

\subsection{Preparation of nanoparticles}

Forty milliliters of $\mathrm{AgNO}_{3}(0.25 \mathrm{M})$ were then added to $10 \mathrm{~mL}$ of $K$. galanga extract and mixed at room temperature $\left(25^{\circ} \mathrm{C}\right)$ for 24h. AgKG-NPs were gradually obtained during the incubation period. Throughout the reduction process, all solutions were kept at a room temperature in the dark to avoid any photochemical reactions. The obtained colloidal suspensions of AgKG were then centrifuged at $12,000 \mathrm{rpm}$ for $10 \mathrm{~min}$ and washed four times to remove silver ion residue. The precipitate nanoparticles were then dried overnight at $30^{\circ} \mathrm{C}$ under vacuum.

\subsection{Morphology determination}

UV-Vis spectra were recorded over 300-800 nm range with a UV-vis spectrophotometer (Shimadzu) with samples in quartz cuvette. Deionized water was used as blank. The spectra recorded were then re-plotted using Origin 6.1 version. The FT IR spectra were recorded over the range of $400-4,000 \mathrm{~cm}^{-1}$ using Shimazdu IR-408 spectrometer. Electron paramagnetic resonance (EPR) was recorded for free radical analysis on JEOL JES-FA200 ESR spectrometer with Xband microwave unit. SEM images were recorded on FEI-QUANTA-250 electron microscope. The sample of AgKG was adsorbed on a carbon sheet and loaded on the microscope. The sizes of particles were measured with the software IMAGE J. The EDX analysis was carried out on EDAX Energy Dispersion X-ray spectrometer (FIE) for the purity and the chemical composition of AgNPs. The shape and size of the particles were measured with transmission electron microscopy using JEOL JEM-2100 equipped with selected area electron diffraction pattern (SAED). 


\section{Results and Discussion}

Noble metals are known to exhibit unique optical properties due to the excitation of surface plasmon vibrations. On adding the rhizomes extract of $K$. galanga to the colorless silver nitrate solution, the solution turned brown in colour. It showed reduction of silver ions and formation of stable AgNPs. AgNPs exhibited yellowish brown colour in aqueous solution due to excitation of surface plasmon vibrations in silver nanoparticles[22,39]. The appearance of SPR peak at $422 \mathrm{~nm}$ provided a convenient spectroscopic signature for formation of AgNPs [40] (Fig.1).

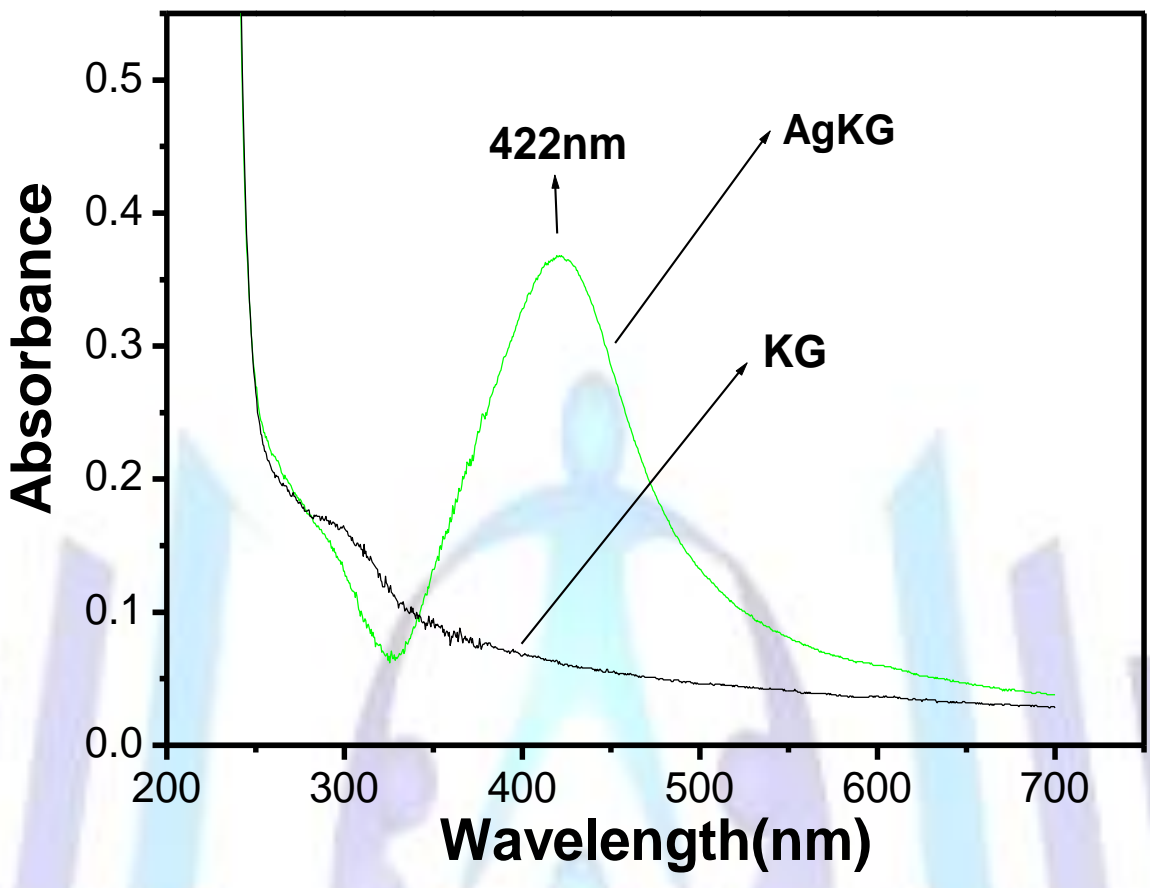

Fig.1 The UV-Vis spectrum of AgKG NPs

The EPR spectra of AgKG NPs was found to be confined in a single line which showed presence of an unpaired electron indicating of silver in neutral state at room temperature (Fig. 2). The EPR splitting factor of AgKG NPs was caliberated at $\mathrm{g}=2.0023$, which confirmed the reduction of $\mathrm{Ag}^{+}$ion, i.e. formation of $\mathrm{Ag} \mathrm{NPs}$.

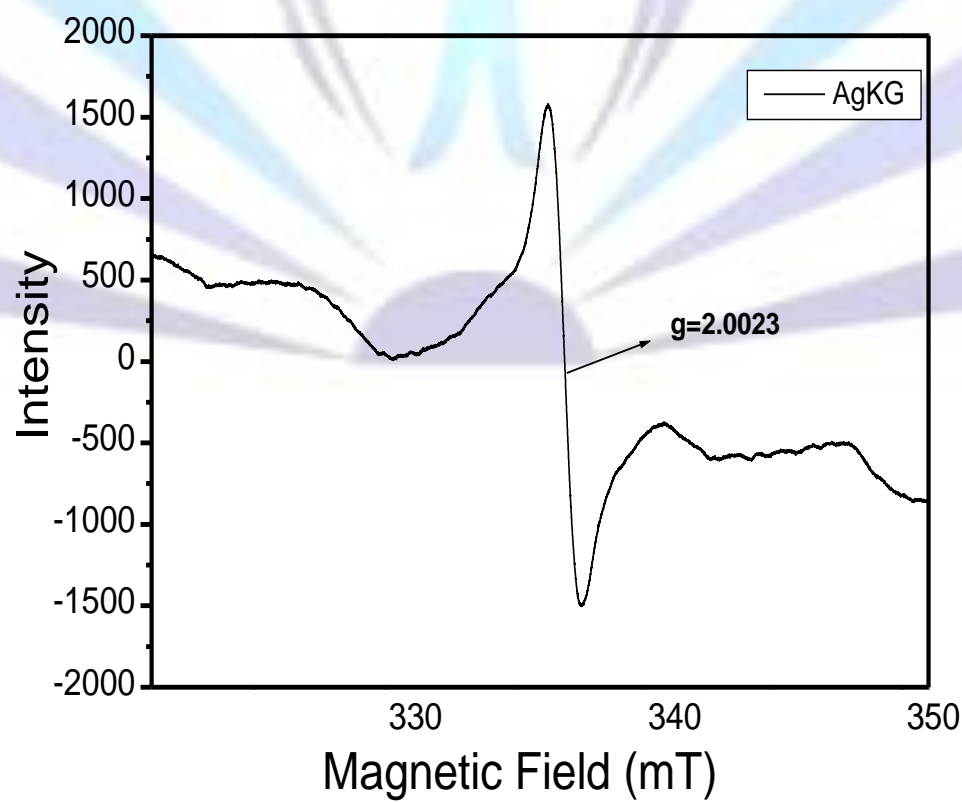

Fig.2 EPR spectrum of AgKG NPs at room temperature

The FT-IR spectra of AgKG showed significant change in their respective vibrational spectra of KG (Fig. 3). FTIR spectrum of AgKG displayed absorption bands at $3208,1679,1595,1391,1313,1015$ and $773 \mathrm{~cm}-1$. The bands 
observed at 1679 and $1595 \mathrm{~cm}^{-1}$ are assigned to the stretching vibrations of the $\mathrm{C}=\mathrm{C}$ and $\mathrm{C}=\mathrm{O}$ bonds, respectively. The bands appeared at 1391,1313 and $1015 \mathrm{~cm}-1$ may be assigned to $-\mathrm{C}=\mathrm{O},-\mathrm{C}=\mathrm{C},-\mathrm{C}-\mathrm{N},-\mathrm{C}-\mathrm{O}$ and $-\mathrm{C}-\mathrm{O}-\mathrm{C}$ stretching respectively. FT-IR study revealed that the carboxyl $(-\mathrm{C}=\mathrm{O})$, hydroxyl $(-\mathrm{OH})$, and amine $(\mathrm{N}-\mathrm{H})$ groups in the rhizome extracts were mainly involved in reduction of $\mathrm{Ag}^{+}$ions to $\mathrm{Ag}^{0}$ nanoparticles. FTIR analysis was also performed to identify the possible biomolecules present in extracts of $K$. galanga that are responsible for the reduction of the metal precursors as well as for the stabilization of NPs. Moreover, FTIR data revealed the presence of freely water-soluble compounds in this plant.

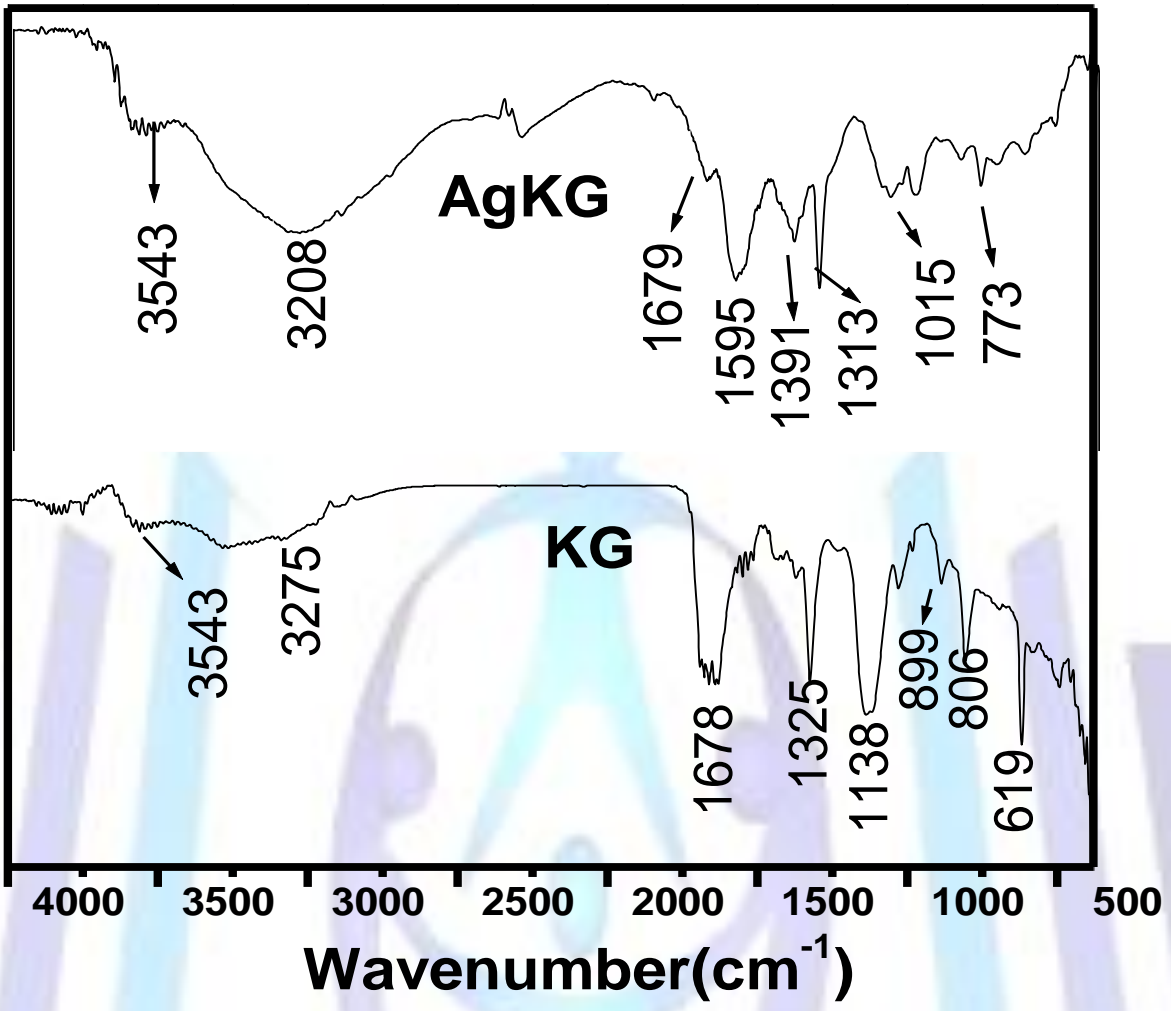

Fig. 3 FT-IR spectrum of aq. extract of $\mathrm{KG}$ and AgKG

EDX profile (Fig. 4) showed strong silver signal along with a weak oxygen and carbon peak, which may originate from the biomolecules that are bound to the surface of the silver nanoparticles.

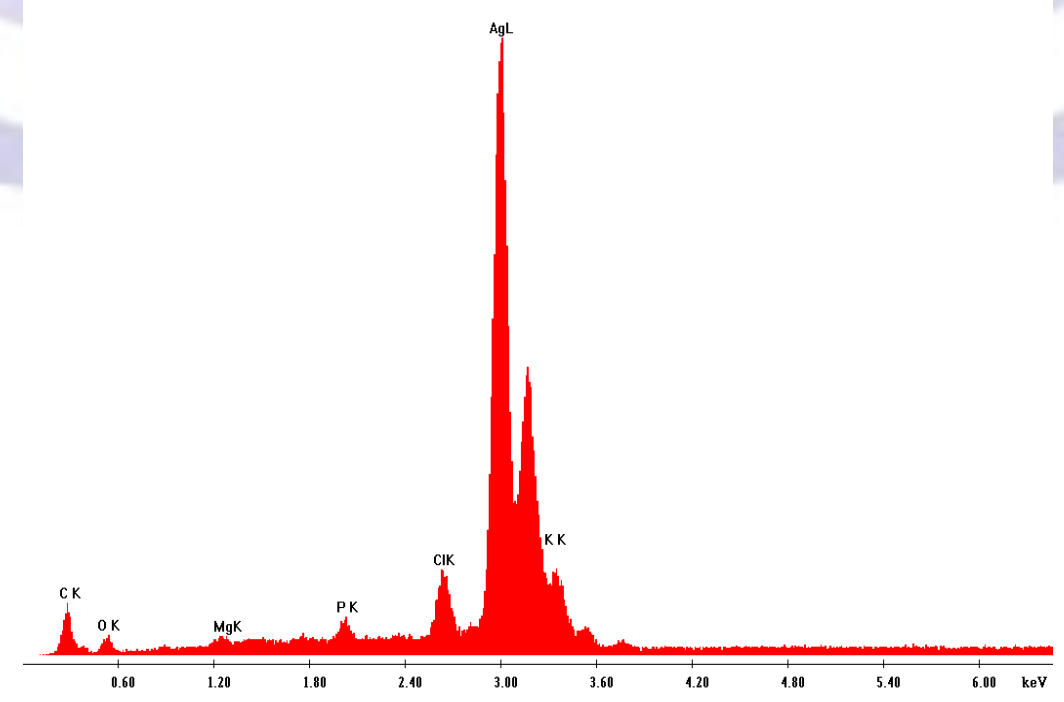

Fig. 4 EDX spectrum of AgKG

SEM image was shown in Fig. 5 that relatively spherical nanoparticles were formed. The morphology and crystalline phase of the NPs were further confirmed by transmission electron microscopy (TEM) images, selected area 
electron diffraction (SAED). In the selected area electron diffraction (SAED) pattern recorded from the silver nanoparticles (Fig. 6), the ring-like diffraction pattern indicates that the particles are crystalline. The diffraction rings could be indexed on the basis of the fcc structure of silver. Four rings arise due to reflections from (111), (200), (220), and (311) lattice planes of fcc silver, respectively.

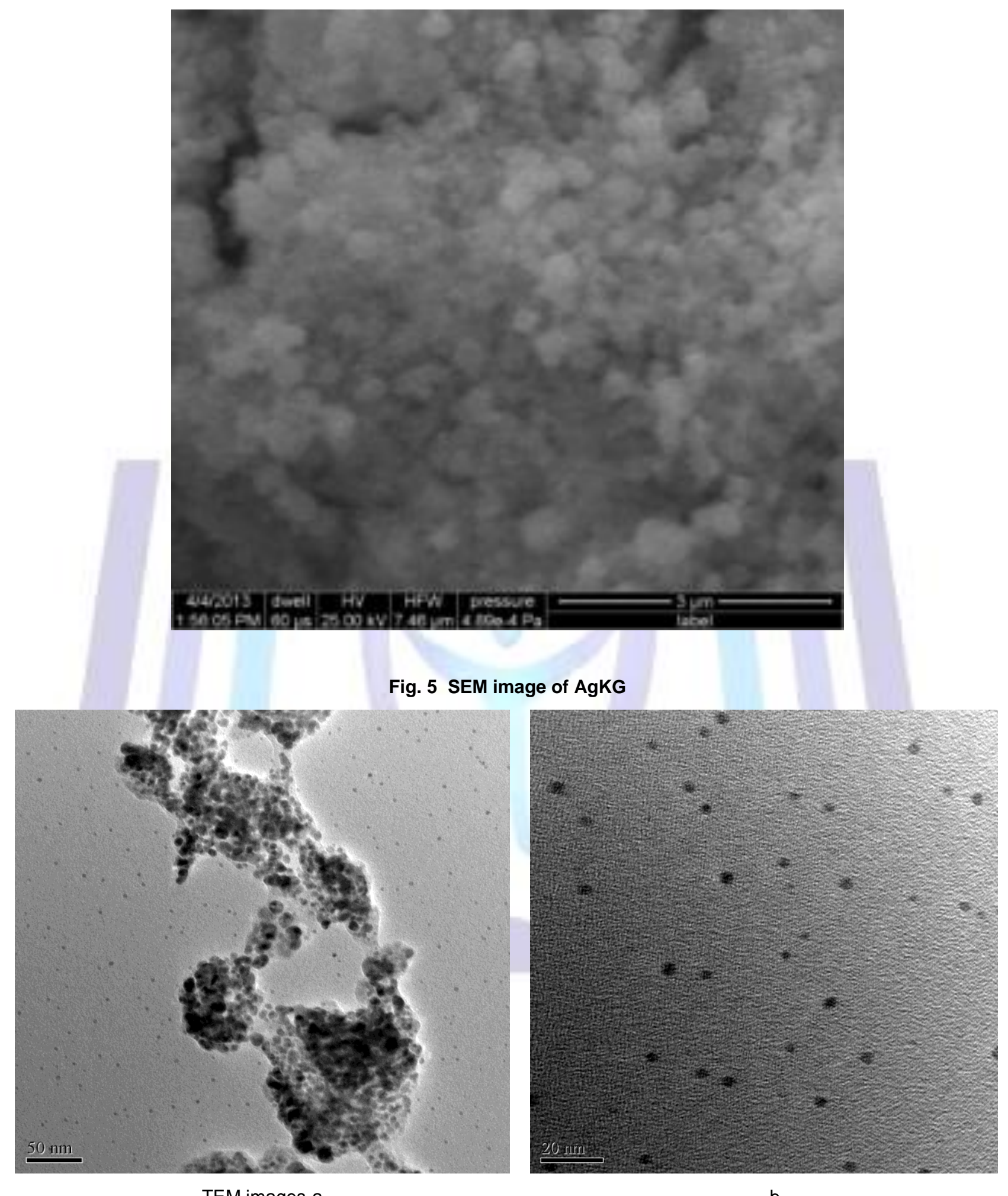

TEM images-a 


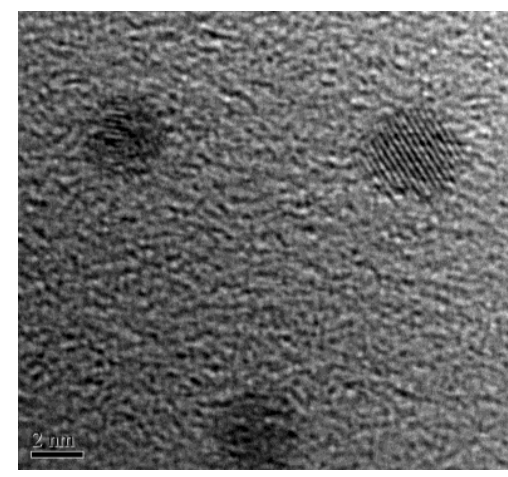

C

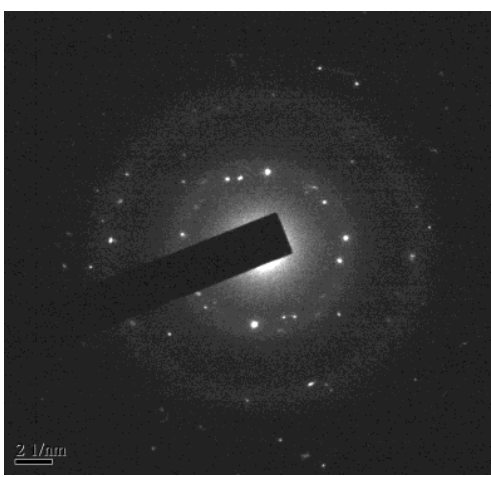

d (SAED pattern)

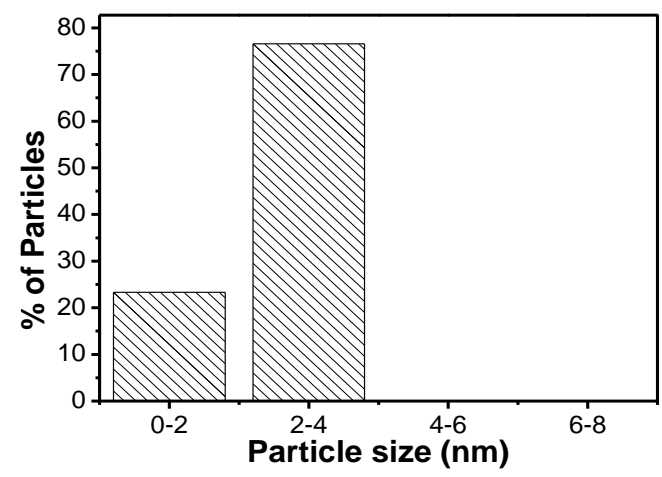

e (Particle size distribution)

Fig.6 TEM images of - a, b, c, d and Particle size distribution (e)

\section{Conclusion}

Silver nanoparticles were successfully prepared using $K$. galanga rhizome extract as the starting raw material. The method involved the bioreduction of silver ions by the plant extract and the secondary metabolites played the role of potential reducing agent. The appearance of SPR peak at $422 \mathrm{~nm}$ provided a convenient spectroscopic signature for the formation of silver nanoparticles. The EPR spectra of AgKG NPs showed the presence of an unpaired electron in silver neutral state at room temperature. FT-IR study revealed that the carboxyl $(-\mathrm{C}=\mathrm{O})$, hydroxyl $(-\mathrm{OH})$, and amine $(\mathrm{N}-\mathrm{H})$ groups in the rhizome extracts were mainly involved in reduction of $\mathrm{Ag}^{+}$ions to $\mathrm{Ag}^{0}$ nanoparticles. TEM images confirmed the surface morphology, shape and size of the silver nanoparticles. Average size range estimated from our studies was 2 to $4 \mathrm{~nm}$. It consisted of a spherical like particles.

\section{ACKNOWLEDGMENTS}

The authors acknowledge SAIF, NEHU for TEM; Physics department, Manipur University for SEM and EDX Satyavama thanks UGC, New Delhi for BSR Fellowship

\section{REFERENCES}

[1] P. Mohanpuria, N.K. Rana, S.K. Yadav, J. Nanopart. Res. 10 (2008) 507.

[2] M.B. Mohamed, V. Volkov, S. Link, M.A.E. Sayed, Chem. Phys. Lett. 317 (2000) 517.

[3] M. Rai, A. Yadav, A. Gade, Biotechnol. Adv. 27 (2009)76.

[4] K. Shameli, M.B. Ahmad, W.M.Z. Wan Yunus, N.A. Ibrahim, Y. Gharayebi, S. Sedaghat, Int. J. Nanomed. 5 (2010) 1067.

[5] K. Shameli, M.B. Ahmad, W.M.Z. Wan Yunus, A. Rustaiyan, N.A. Ibrahim, M. Zargar, Y. Ab- dollahi, Int. J. Nanomed. 5 (2010) 875.

[6] Y.H. Zhang, F. Chen, J.H. Zhuang, Y. Tang, D.J. Wang, Y.J. Wang, A.G. Dong, N. Ren, Chem. Commun. $2002,2814$.

[7] K. Szczepanowicz, J. Stefan' ska, R.P. Socha, Physicochem. Probl. Miner. 45 (2010) 85.

[8] K. Shameli, M.B. Ahmad, M. Zargar, W.M.Z. Wan Yunus, A. Rustaiyan, N.A. Ibrahim, Int. J. Nanomed. 6 (2010) 581.

[9] K. Shameli, M.B. Ahmad, W.M.Z. Wan Yunus, N.A. Ibrahim, Int. J. Nanomed. 5 (2010) 743.

[10] K. Shameli, M.B. Ahmad, M. Zargar, W.M.Z. Wan Yunus, N.A. Ibrahim, Int. J. Nanomed. 6 (2011) 331.

[11] K. Shameli, M.B. Ahmad, S.D. Jazayeri, S. Sedaghat, P. Shabanzadeh, H. Jahangirian, M. Mahdavi, Y. Abdollahi, Int. J. Mol. Sci. 13 (2012) 6639

[12] I. Pastoriza Santos, L.M. Liz Marza'n, Langmuir 15 (1999) 948.

[13] M.B. Ahmad, K. Shameli, W.M.Z. Wan Yunus, N.A. Ibrahim, Aust. J. Basic Appl. Sci. 4 (2010) 2158.

[14] P. Setua, R. Pramanik, S. Sarkar, J. Phys. Chem. B. 114 (2010) 7557.

[15] P. Praus, M. Turicova', M. Klementova', J. Braz. Chem. Soc. 20 (2009) 1351.

[16] L. Sun, Z. Zhang, H. Dang, Mater. Lett. 57 (2003) 3874.

[17] J.L. Gardea Torresdey, J.G. Parsons, K. Dokken, J.R. Peralta Videa, H. Troiani, P. Santiago, M. Jose Yacaman, Nano Lett. 2 (2002) 397. 
[18] J.L. Gardea Torresdey, E. Gomez, J.R. Peralta Videa, J.G. Parsons, H. Troiani, M. Jose Yacaman, Langmuir 19 (2003) 1357.

[19] S.R. Bonde, D.P. Rathod, A.P. Ingle, R.B. Ade, A.K. Gade, M.K. Rai, Nanoscience Methods 1 (2012) 25-36.

[20] S.P. Chandran, M. Chaudhary, R. Pasricha, A. Ahmad, M. Sastry, Biotechnology Program 22 (2006) 577-583.

[21] S. Li, Y. Shen, A. Xie, X. Yu, L. Qiu, L. Zhang, Q. Zhang, Green Chemistry 9 (2007) 852-858.

[22] S.S. Shankar, A. Rai, A. Ahmad, M. Sastry, Journal of Colloid Interface Science 275 (2004) 496-502.

[23] J.Y. Song, B.S. Kim, Bioprocess Biosyst. Engineering 32 (2009) 79-84.

[24] M. Sathishkumar, K. Sneha, S.W. Won, C.W. Cho, S. Kim, Y.S. Yun, Colloid Surf. B 73 (2009) 332-338.

[25] V. Kumar, S.K. Yadav , J. Chem. Technol. Biotechnol. 84 (2009) 151-157.

[26] L. Jia, Q. Zhang, Q. Li and H. Song, Nanotechnology, 2009, 20, 385601.

[27] H. Cong, J. A. Porco, Jr. ACS Catal. 2 (2012) 65-70.

[28] I. A. Wani, S. Khatoon, A. Ganguly, J. Ahmed, T. Ahmada, Colloids and Surfaces B: Biointerfaces 101 (2013) $243-250$.

[29] S. Das, J. Das, A. Samadder, S. S. Bhattacharyya, D. Das, A. R. Khuda-Bukhsh Colloids and Surfaces B: Biointerfaces 101 (2013) 325- 336.

[30] D. Jeevitha, K. Amarnath, Colloids and Surfaces B: Biointerfaces 101 (2013) 126-134.

[31] C. Aguzzi, G. Sandri, C. Bonferoni, P. Cerezo, S. Rossi, F. Ferrari, C. Caramella, C. Viseras, Colloids and Surfaces B: Biointerfaces 113 (2014) 152- 157.

[32] C.E. Rajendra, G.S. Magada-um, M.A. Nadaf, S.V. Yashoda, M. Manjula, Int. J. Pharma. Phytochem. Res. 3 (2011) 61-63.

[33] S. Tewtrakul, S. Yuenyongsawad, S. Kummee, L. Atsawajaruwan, Songklanakarin J. Sci. Technol. 27 (2005) 503507.

[34] R.A. Mustafa, H.A. Abdul, S. Mohamed, F.A. Baker, J. Food Sci., 75 (2010) C28-C35.

[35] R. Othman, H. Ibrahim, M.A. Mohd., M.R. Mustafa, K. Awang, Phytomedicine, 13 (2006) 61-66.

[36] S.K. Nerle, S.G. Torne, Indian Drugs, 21(1984) 236.

[37] K.C. Wong, K.S. Ong, C.L. Lim, Composition Flavour and Fragrance J. 7 (1992) 263.

[38] C. Pandji, C. Grimm, V. Wray, L. Witte, P. Proksch, Phytochemistry, 34 (1993) 415-419.

[39] A. Ahmad, P. Mukherjee, S. Senapati, D. Mandal, M.I. Khan, R. Kumar, Colloids Surf. B: Biointerfaces 28 (2003) 313 318.

[40] V.K. Vidhu, Daizy Philip, Spectrochim. Acta A 117 (2014) 102-108. 